\title{
IMITAÇÃO VOCAL E NOMEAÇÃO DE FIGURAS EM DEFICIENTES AUDITIVOS USUÁRIOS DE IMPLANTE COCLEAR: ESTUDO EXPLORATÓRIO
}

\section{VOCAL IMITATION AND PICTURE NAMING IN USERS OF COCHLEAR IMPLANT: AN EXPLORATORY STUDY}

\author{
Ana Claudia Moreira Almeida Verdu ${ }^{1}$ \\ UNIVERSIDADE ESTADUAL PAULISTA \\ Maria Cecília Bevilacqua ${ }^{2}$ \\ UNIVERSIDADE DE SÃO PAULO \\ Deisy Das GRaÇas de SOUZA ${ }^{3}$ \\ UNIVERSIDADE FEDERAL DE SÃO CARLOS \\ Fabiana Cristina de SOUZA ${ }^{4}$ \\ UNIVERSIDADE ESTADUAL PAULISTA
}

\begin{abstract}
RESUMO
O objetivo deste trabalho foi verificar se o ensino do comportamento ecoico combinado com uma tarefa de emparelhamento entre palavras ditadas e figuras favorece a emergência da nomeação de figuras, em crianças surdas, usuárias de implante coclear. O emparelhamento auditivo-visual com ouvintes geralmente ocasiona a nomeação das figuras; entretanto, usuários de implante apresentam dificuldade em nomear, mesmo depois de apresentarem desempenho preciso nas tarefas de seleção. Neste estudo, o ensino do comportamento ecoico de três palavras foi sobreposto à tarefa de emparelhamento (para duas crianças do Grupo 1) ou precedeu a tarefa de emparelhamento (para duas crianças do Grupo 2). Uma palavra ditada era apresentada por meio do alto-falante do computador e a criança era instruída a repetir a palavra; se errasse, o experimentador apresentava pistas orofaciais. Após o ensino do ecoico e de relações condicionais entre palavras ditadas e figuras convencionais $(\mathrm{AB})$ e entre as mesmas palavras e figuras abstratas (AC), as quatro crianças formaram classes entre figuras convencionais e figuras abstratas (Testes BC/CB), e a nomeação das figuras aumentou consideravelmente em relação à linha de base. O ensino de ecoico, combinado com procedimentos de discriminação condicional auditivo-visual, pode promover simultaneamente compreensão auditiva e inteligibilidade de fala em usuários de implante.
\end{abstract}

Palavras-chave: comportamento verbal, nomeação de figuras, comportamento ecoico, deficiência auditiva, implante coclear.

\begin{abstract}
The aim of this study was to determine whether the teaching of echoic behavior combined with a task of matching between dictated words and pictures, favors the emergence of picture naming in deaf children with cochlear implant. With listeners the matching auditory-visual generally caused the figures naming, however, implant users have difficulty in naming, even when present accurate performance on tasks of selection. In this study, the teaching of echoic behavior of three words was overlap the task of matching (for two children in Group 1) or prior to the task of matching (for two children in Group 2). A word was dictated by the middle of the speaker of the computer and the child was instructed to repeat the word; if a mistake was made, the experimenter presented orofacial clues. After teaching the echoic and conditional relations between dictated words and figures conventional (AB) and between the same words and abstract figures (AC), the four children formed classes of words and pictures (Tests $\mathrm{BC} / \mathrm{CB}$ ) and the naming pictures increased considerably compared to baseline. The teaching of echoic procedures combined with auditory-visual conditional discrimination can promote both listening and speech intelligibility in cochlear implant users.
\end{abstract}

Keywords: verbal behavior, pictures naming, echoic behavior, impaired hearing, cochlear implant.

\footnotetext{
${ }^{1}$ Programa de Mestrado em Psicologia do Desenvolvimento e Aprendizagem, Bauru/SP. Av. Eng ${ }^{\circ}$ Luiz Edmundo Carrijo Coube, 14-01, Vargem Limpa, CEP 17033-360, Bauru/SP. Tel.: (14) 3103-6087. E-mail: anaverdu@ffc.unesp.br

${ }^{2}$ Programa de Mestrado em Fonoaudiologia, Bauru/SP.

${ }^{3}$ Programa de Pós-graduação em Psicologia, São Carlos/SP.

${ }^{4}$ Departamento de Psicologia, Bauru/SP.
} 
O implante coclear permite que crianças deficientes auditivas submetidas à extrema privação dessa modalidade sensorial passem a detectar sons, incluindo sons da fala humana. Outros desempenhos auditivos mais complexos, como a discriminação, o reconhecimento, a compreensão, a memória auditiva, requerem aprendizagem (Almeida-Verdu, 2002). Não só a severidade da deficiência auditiva, mas a época em que foi adquirida tem papel importante na aprendizagem dessas funções auditivas. Nesse caso, estabelecem-se aí alguns problemas de pesquisa que se caracterizam pelos efeitos do implante coclear sobre o desenvolvimento da função simbólica envolvendo estímulos sonoros (compreensão), sobre a aprendizagem de novas relações entre estímulos sonoros e outros eventos (reconhecimento de palavras), assim como sobre a vocalização de novas palavras (nomeação de eventos). De acordo com a audiologia, a linguagem pode ser diferenciada de duas formas: 1) linguagem receptiva, que diz respeito ao modo como uma pessoa reage à ocorrência de linguagem, à compreensão do que os outros dizem; 2) e linguagem expressiva, que diz respeito ao meio de ocorrência e à capacidade de fala inteligível (Stuchi, Nascimento, Bevilacqua, \& Brito Neto, 2007).

Pesquisas no âmbito da audiologia têm demonstrado os beneficios do implante na aquisição rápida de habilidades receptivas. É, usualmente, no decorrer de um ano que o implante coclear permite o desenvolvimento dessas funções, de tal forma que o desempenho de crianças implantadas no reconhecimento de palavras atinge os níveis de seus pares ouvintes (Bevilacqua, 1998; Moret, Bevilacqua, \& Costa, 2007; Svirsky, Robbins, Kirk, Pisoni, \& Miyamoto, 2000). Contudo, esses estudos demonstram que as habilidades expressivas não acompanham o mesmo ritmo, e atrasos mais severos ocorrem principalmente com aquelas crianças em que a privação de sons está presente desde o nascimento, ou antes da aquisição de repertórios verbais em relação àquelas em que a deficiência auditiva ocorreu depois da aquisição de repertórios verbais (Löhle, Holm, \& Lehneardt, 1999; Osberger, 1993; Svirsky et al., 2000; Truy, Lina-Granade, Jonas, Martinon, Maison, Girard, Porot, \& Morgon, 1998). Por isso, tornam-se importantes ações voltadas para evitar ou minimizar os riscos de atrasos.

Um grande componente da (re)habilitação de deficientes auditivos que receberam o implante coclear consiste em um treino para estabelecer as funções simbólicas de estímulos auditivos recebidos pelo implante (da Silva, de Souza, de Rose, Lopes Jr., Bevilacqua, \& McIlvane, 2006). O paradigma da equivalência de estímulos fornece um critério operacional para distinguir verdadeiras relações simbólicas de meras relações do tipo "se-então". Se, por exemplo, um participante aprende as discriminações auditivo-visuais entre uma palavra falada e uma figura $(A B)$ e entre a mesma palavra falada e outra figura (AC) e, subsequentemente, demonstra a emergência das relações visual-visual entre as figuras (BC e CB), sem ensino explícito dessas discriminações, então esse resultado indica a formação de classes de equivalência e verdadeiras relações simbólicas (Sidman \& Tailby, 1982).

Um primeiro estudo com o objetivo de estender a metodologia das relações de equivalência ao estudo de relações entre estímulos sonoros e visuais e funções simbólicas em implantados foi conduzido por da Silva et al. (2006). Duas crianças pós-linguais e duas pré- 
-linguais receberam ensino em relações condicionais entre figuras $(\mathrm{AB}$ e $\mathrm{AC})$ que consistiam em letras gregas exibidas na tela de um microcomputador e todas demonstraram as relações ensinadas e derivadas atestando as relações de equivalência (BC e CB). Em seguida, um conjunto de estímulos sonoros foi apresentado via estimulação direta na cóclea (uma sequência de cinco pulsos durante um segundo) e foi conduzido o ensino que estabeleceu as relações condicionais auditivo-visuais DC; então, foram testadas as relações de equivalência auditivo-visuais DA e DB. Os resultados dos participantes pós-linguais demonstraram a aprendizagem das relações envolvendo pulsos elétricos (DC) pelo procedimento de emparelhamento de acordo com o modelo, mas não demonstraram a emergência das novas relações auditivo-visuais (DA e DB). Os participantes pré-linguais sequer aprenderam as relações com estímulos elétricos. Embora o aspecto promissor do estudo tenha sido a condução da pesquisa em controle de estímulos em rotina de hospital e tenha demonstrado emergência de relações simbólicas visual-visual em implantados, o estudo impôs algumas questões sobre a aprendizagem relacional envolvendo estímulos auditivos em surdos que receberam o implante coclear. Dentre essas questões, destacou-se verificar sob quais condições surdos que receberam o implante coclear aprenderiam relações auditivo-visuais e demonstrariam relações de equivalência decorrentes dessa aprendizagem.

Uma sequência de quatro estudos foi conduzida por Almeida-Verdu, Huziwara, de Souza, de Rose, Bevilacqua, Lopes Jr., Alves, e McIlvane (2008) e avaliou o potencial de crianças com surdez neurossensorial que receberam o implante coclear de exibirem re- lações de equivalência entre figuras e palavras ditadas pelo procedimento de emparelhamento de acordo com o modelo. Dez crianças com surdez pré-lingual e quatro com surdez pós-lingual foram estudadas e todas aprenderam as relações entre palavra ditada e figuras ensinadas. Nove crianças demonstraram a formação de classes; somente uma criança falhou em demonstrar a formação de classes pelo procedimento original, mas demonstrou a formação de classes com uma replicação sistemática envolvendo estímulos com história extraexperimental.

As diferenças obtidas na aquisição de relações condicionais auditivo-visuais pelas crianças deficientes auditivas pré-linguais que participaram dos estudos de Almeida-Verdu et al. (2008) e aquelas que participaram do estudo de da Silva et al. (2006) podem ser função de algumas variáveis, tais como as propriedades físicas dos estímulos utilizados e o procedimento adotado. Em relação às propriedades físicas dos estímulos, da Silva et al. (2006) utilizaram estímulos elétricos apresentados diretamente na cóclea como estímulos sonoros e letras gregas como estímulos visuais, e Almeida-Verdu et al. (2008) utilizaram estímulos linguísticos como estímulos sonoros e figuras. O uso de estímulos linguísticos em vez de estímulos elétricos pode ter facilitado o desempenho em tarefas de discriminação auditivo-visual. Em relação ao procedimento, Almeida-Verdu et al. (2008) adotaram procedimentos de modelagem de controle de estímulos, como o fading e o ensino por exclusão, relatados também em estudos sobre aprendizagem sem erros (Sidman, 1985; Stoddard, de Rose, \& McIlvane, 1986; Terrace, 1963, 1966). Essas características do procedimento podem ter contribuído para a 
aprendizagem das relações auditivo-visuais pelas crianças com deficiência auditiva pré-linguais que participaram dos estudos conduzidos por Almeida-Verdu et al. (2008).

Ao final de cada um dos Estudos 1, 2 e 3 de Almeida-Verdu et al. (2008), foram conduzidos testes de nomeação de figuras, mas as crianças não demonstraram resultados consistentes com os resultados obtidos nos testes de equivalência. De maneira geral, elas emitiam vocalização semelhante diante de figuras associadas à mesma palavra, mas a vocalização não correspondia à palavra ditada.

Esses dados podem ser entendidos à luz do desenvolvimento da audição, avaliado por Gaia (2005), que estudou longitudinalmente o desempenho de crianças implantadas pré-linguais em tarefas de reconhecimento de palavras, de nomeação de figuras e de imitação vocal, quer esses participantes estivessem ou não recebendo ensino sistemático ou atendimento fonoaudiológico. Os resultados obtidos por Gaia demonstraram que os participantes tenderam a apresentar melhores desempenhos nos testes de reconhecimento de palavras (que requeriam apenas respostas de seleção) do que nos dois outros testes, que requeriam vocalizações. Esses resultados indicam que o fato de o ouvir estar estabelecido (e o reconhecimento, demonstrado) não é condição suficiente para que o indivíduo seja capaz de falar a palavra que ouve. Em outras palavras, embora o falar dependa do ouvir (o ouvinte precisa detectar uma palavra falada, discriminar entre palavras diferentes, relacionar uma palavra a seus referentes etc.), a fala, seja como nomeação, seja como imitação, depende de condições adequadas para o seu ensino. Há várias evidências empíricas na literatura sobre a independência funcional entre operantes verbais, dentre eles o ouvir e o falar (Cuvo \& Riva, 1980; Eikeseth \& Nesset, 2003; Guess, 1969; McMorrow, Foxx, Faw, \& Bittle, 1987). Essa literatura tem demonstrado que o ensino do ouvir pode ser considerado uma condição necessária, mas não suficiente para a aprendizagem do falar; contudo, tanto o ouvir quanto o falar são aprendidos após condições de ensino particulares. Considerando as habilidades necessárias para comunicação em uma comunidade verbal de falantes e ouvintes e as habilidades de produção de fala demonstradas em crianças surdas implantadas pré-linguais, questiona-se sob quais condições essa população apresentaria a nomeação de figuras precisa, isto é, com correspondência ponto a ponto com a palavra ditada pela comunidade verbal. Após o ensino de relações entre a palavra ditada e a figura, essa literatura tem demonstrado que o procedimento de imitação de palavras tem sido efetivo para a posterior nomeação em populações com diferentes necessidades especiais de ensino.

O objetivo deste trabalho foi verificar o efeito do ensino da imitação de palavras ditadas sobre a nomeação de figuras, quando empregado em dois momentos diferentes do ensino de relações condicionais entre palavras ditadas e figuras.

\section{MÉTOdo}

\section{Participantes}

Participaram do estudo seis crianças com idades entre sete anos e dois meses e oito anos e três meses, com deficiência auditiva pré-lingual bilateral profunda e que receberam o implante coclear modelo Nucleus 24 ®. A idade auditiva, calculada a partir da data do recebimento do implante até a data da pesquisa, foi superior a três anos. A Tabela 1 
apresenta uma caracterização dos participantes.Antes da participação no experimento, eles foram avaliados em reconhecimento de palavras que forneceu uma medida de seu nível de entrada em linguagem receptiva e auxiliou a selecionar os estímulos auditivos que compuseram as fases de ensino e teste. $\mathrm{O}$ desempenho dos participantes foi inferior a $60 \%$ de acertos, e uma participante apresentou desempenho bem inferior (TAL; $<10 \%$ de acertos).

\section{Tabela 1}

Caracterização geral dos participantes: identificação (fictícia), idade cronológica (em anos e meses), idade auditiva, etiologia da surdez e escore em teste de reconhecimento de palavras

\begin{tabular}{llllll}
\hline Nome & Idade & Grupo & $\begin{array}{l}\text { Idade } \\
\text { Auditiva }^{a}\end{array}$ & $\begin{array}{l}\text { Etiologia } \\
\text { da Surdez }\end{array}$ & $\begin{array}{l}\text { Reconhe- } \\
\text { cimento } \\
\text { de Palavras }\end{array}$ \\
\hline Nai & 7 a $6 \mathrm{~m}$ & 1 & 3 a $0 \mathrm{~m}$ & Congênito & $<60 \%$ \\
Nat & 7 a $2 \mathrm{~m}$ & 1 & 5 a $5 \mathrm{~m}$ & Congênito & $<40 \%$ \\
Cam & 7 a $11 \mathrm{~m}$ & 2 & 5 a $6 \mathrm{~m}$ & Congênito & $<50 \%$ \\
Tal & 8 a $3 \mathrm{~m}$ & 2 & 6 a $5 \mathrm{~m}$ & Congênito & $<10 \%$ \\
\hline
\end{tabular}

${ }^{a}$ A idade auditiva foi definida pelo tempo de uso do implante coclear até o início da coleta de dados. Foi calculada subtraindo-se o tempo de privação auditiva da idade do participante.

\section{Condições de coleta e materiais}

Participaram das sessões de coleta de dados o experimentador e um participante. As sessões também foram registradas em fita de videoteipe (VHS). A coleta de dados e o registro das sessões foram realizados com o auxílio de um microcomputador Macintosh (IBook G4). Para este estudo, foi utilizado o programa de computador MTS® versão 11.6.7 (Dube, 1991), com o qual foram programadas as rotinas de ensino e teste e as respostas dos participantes eram registradas. $\mathrm{O}$ programa exibia estímulos sonoros gravados de sons da fala humana (palavras convencionais dissílabas) e estímulos visuais (figuras convencionais e abstratas). A Tabela 2 ilustra os estímulos modelo

Tabela 2

Estímulos modelo e de comparação adotados nas condições experimentais

\begin{tabular}{|c|c|c|c|}
\hline Par- & Estí- & $\begin{array}{l}\text { Modelo } \\
\text { Auditivo }\end{array}$ & $\begin{array}{c}\text { Comparações } \\
\text { Visuais }\end{array}$ \\
\hline & $\mathrm{mu}$ & A & B \\
\hline
\end{tabular}

Grupo 1

Nai /sofál 2 /boca/ 1 /boda/

Grupo 2

Cam 2 /carro/ /cobra/


e de comparação adotados nas condições experimentais para os participantes.

\section{Procedimento geral}

O procedimento adotado consistiu em uma sequência de tentativas discretas (instrução, desempenho, consequência programada e intervalo entre tentativa). Foram realizadas cinco fases: avaliação do nível de entrada em reconhecimento de palavras, pré-teste de nomeação, ensino de imitação de palavras e de relações entre palavra ditada e figura, teste de formação de classes e pós-teste de nomeação. $\mathrm{O}$ procedimento que vigorou foi o emparelhamento de acordo com o modelo. Um estímulo com função de modelo era exibido no centro da tela do monitor, e três estímulos de comparação eram exibidos em três dos quatro vértices da tela. A tarefa de cada participante era escolher, dentre os estímulos de comparação, aquele que se relacionava com o modelo. As tentativas empregavam modelos auditivos (relação auditivo-visual) ou visuais (relação visual-visual). Algumas tentativas exigiam, ainda, respostas de vocalização na presença de um estímulo auditivo (imitação vocal) ou visual (nomeação). Os estímulos com função de modelo eram apresentados sucessivamente, e os estímulos com função de comparação eram apresentados simultaneamente. Nas fases de ensino, eram apresentadas consequências diferenciais para acerto e erro; nas fases de teste, não eram apresentadas consequências programadas.

\section{Avaliação do nível de entrada em reconhecimento de palavras}

O objetivo dessa fase foi selecionar palavras para compor as fases posteriores de ensino e testes. O reconhecimento de palavras era avaliado pela exposição dos participantes a relações condicionais auditivo-visuais em que uma palavra era ditada como modelo e três figuras eram ditadas como comparação. Cada participante foi exposto à avaliação de 30 palavras dissílabas organizadas em três blocos com 10 tentativas cada um. Em cada tentativa, o estímulo auditivo era apresentado simultaneamente a um quadrado azul no centro da tela; um clique no mouse fazia com que três estímulos de comparação fossem exibidos em três dos quatro vértices da tela, sendo uma das figuras correspondente ao modelo. A palavra ditada era apresentada por até quatro vezes, em intervalos de quatro segundos. Se o participante selecionasse uma figura, interrompia-se a sequência de até quatro apresentações da palavra ditada e seguia-se uma tela branca de intervalo entre tentativas com duração de um segundo, independente de acerto ou erro. Se o participante não selecionasse uma das três figuras disponíveis, após a quarta apresentação da palavra ditada o computador exibia a tela de intervalo entre tentativas e uma nova tentativa era iniciada. A partir dos resultados dessa avaliação, foram selecionadas três palavras das quais o participante não acertou a seleção da figura correspondente.

\section{Pré-teste de nomeação}

Nessa fase, cada participante era avaliado em nomeação de três figuras convencionais selecionadas do pré-teste, cujo desempenho foi de erro na relação entre palavra ditada e figura. As figuras eram apresentadas, sucessivamente, no centro da tela do computador, e o participante deveria dizer seu nome. $\mathrm{O}$ tempo de apresentação de cada figura era de 16 segundos; caso o participante emitisse uma vocalização, a exibição da figura era 
interrompida e seguia-se a tela de intervalo entre tentativas; no caso do participante não emitir nenhuma vocalização, decorridos 16 segundos, a figura era removida da tela, seguia-se a tela de intervalo entre tentativas e uma nova figura era exibida.

\section{Ensino de imitação de palavras}

Nessa fase, era ensinada a imitação vocal das três palavras selecionadas do pré-teste. Era apresentada uma palavra pelo alto-falante do computador e o participante deveria apresentar imitação vocal com correspondência ponto a ponto com a palavra ditada. Cada palavra era ditada uma vez; caso o participante repetisse a palavra com correspondência pontual com a palavra ditada, isto é, no caso de resposta correta, era apresentada uma nova tentativa; caso a resposta fosse incorreta, a palavra era apresentada pelo experimentador, que fornecia pistas orofaciais (movimentos da face e lábios) e solicitava que o participante repetisse a palavra; caso o participante não emitisse nenhuma resposta, transcorridos 16 segundos, uma nova tentativa era exibida.

O ensino da imitação de palavras ocorreu de forma diferente para dois grupos.

Para o Grupo 1, a imitação era solicitada durante o ensino da relação condicional entre palavra ditada e figura. A tarefa consistia em ditar a palavra, solicitar a imitação de acordo com os critérios descritos e, após a vocalização emitida seguida de pistas orofaciais ou não, o mouse era disponibilizado para que a criança selecionasse a figura correspondente. As tentativas de imitação vocal antecederam em cada uma das tentativas de ensino da relação palavra ditada e figura.

Para o Grupo 2, o ensino da imitação de palavras foi apresentado antes do ensino da relação entre palavra ditada e figura em blocos de nove tentativas, sendo três tentativas de cada uma das três palavras selecionadas para o ensino, organizadas em ordem randômica.

\section{Ensino da relação entre palavra ditada e figura}

Nessa fase, era ensinada a relação entre as mesmas três palavras ditadas e figuras selecionadas do pré-teste e que participaram das fases anteriores. A tarefa consistia na apresentação de uma palavra ditada (dentre três possíveis, apresentadas sucessivamente) pelo alto-falante do computador e na exibição das três figuras convencionais apresentadas simultaneamente, das quais uma era definida como correta. Eram ensinadas as relações $A B$ (A1B1, A2B2, e A3B3), em que A era uma palavra ditada e B, uma figura. Após a aquisição dessa linha de base, ocorria o ensino da relação entre as mesmas palavras ditadas (A) e outras três figuras (C), agora abstratas, constituindo as relações AC (A1C1, A2C2 e A3C3). Assim, ensinavam-se homônimos, isto é, o mesmo nome pode ser relacionado a duas figuras diferentes.

Essa linha de base foi ensinada separadamente. O primeiro bloco exibia oito tentativas da relação A1B1 e, de acordo com a programação, caso nenhum erro ocorresse na seleção da figura definida como correta, o participante era exposto ao segundo bloco de oito tentativas da relação A2B2. O terceiro bloco misturava as relações A1B1 e A2B2 em 16 tentativas. Se algum erro ocorresse no terceiro bloco, o ensino das mesmas relações era conduzido novamente. Se nenhum erro ocorresse, a relação A3 B3 era ensinada, adotando-se o mesmo critério de misturar, após o seu ensino, as três relações (A1B1, A2B2 e A3B3) em um mesmo bloco, composto 
por 24 tentativas. $\mathrm{O}$ ensino das relações $\mathrm{AC}$ (A1C1, A2C2 e A3C3) seguiu os mesmos critérios. Após desempenho de 100\% nesse conjunto de tarefas, o participante era exposto ao bloco que misturava as seis relações auditivo-visuais ( $\mathrm{AB}$ e $\mathrm{AC}$ ) e aos testes de formação de classes (BC e CB).

\section{Testes de formação de classes}

Nessa fase, era avaliado se as figuras (convencionais e abstratas) que foram relacionadas a uma mesma palavra ditada na fase anterior seriam, agora, relacionadas entre si. Essas verificações consistiam no teste de formação de classes com as relações BC (B1C1, B2C2, B3C3) e CB (C1B1, C2B2, C3B3). Para avaliar esse desempenho, de considerar as figuras relacionadas à mesma palavra ditada como equivalentes ou permutáveis entre si, uma figura (p. ex., convencional) era apresentada no centro da tela do computador, e três figuras (p. ex., abstratas) eram apresentadas nos vértices como escolha. A relação inversa também foi avaliada, isto é, se ao apresentar a figura abstrata no centro do monitor o participante escolheria, dentre três convencionais, aquela emparelhada ao mesmo estímulo auditivo que o modelo. Nos blocos que avaliaram as relações BC e CB, eram apresentadas também as relações de linha de base, de tal forma que o bloco era constituído de nove relações $\mathrm{BC}$, nove relações $\mathrm{CB}$ e nove relações $\mathrm{AB} /$ AC. Caso o participante apresentasse erros, as tentativas de linha de base e de testes de formação de classe eram apresentadas em blocos separados, de tal forma que eram apresentados um bloco de 18 tentativas $\mathrm{AB}$ e AC seguidas de 18 tentativas BC e CB. Após essa avaliação, o participante era avaliado em nomeação das seis figuras (três convencionais e três abstratas). Apenas 33,3\% das relações tinham consequência programada, de tal forma que somente o desempenho nas relações de linha de base era reforçado, e os desempenhos nas relações de formação de classe, não. Caso o participante não apresentasse resultados condizentes com a formação de classes, os testes eram reapresentados.

\section{Pós-teste de nomeação}

Nessa fase, as seis figuras (convencionais-B e abstratas-C) eram apresentadas sucessivamente no centro do monitor, e a tarefa do participante era dizer o seu nome, constituindo as relações BD e CD. Era avaliado se esse nome era correspondente àquele ditado no ensino da relação entre palavra ditada e figuras. O mesmo nome deveria ser apresentado para figuras convencionais e abstratas que foram emparelhadas com o mesmo estímulo.

\section{Resultados}

A Figura 1 apresenta o desempenho dos participantes em blocos sucessivos do Grupo 1 nas tarefas de pré-teste de nomeação, ensino de imitação de palavras, desempenho na aquisição das relações condicionais auditivo-visuais, testes de formação de classes e pós-teste de nomeação.

A análise das vocalizações foi realizada a partir do registro em videoteipe. As palavras emitidas pelos participantes foram transcritas e comparadas com as respectivas palavras ditadas pelo alto-falante do computador em relação à quantidade de fonemas/grafemas existentes. Foi obtida, então, a porcentagem de acertos, o que corresponde à relação entre os fonemas emitidos corretamente em um conjunto de tentativas e os fonemas totais 


\section{Grupo 1}

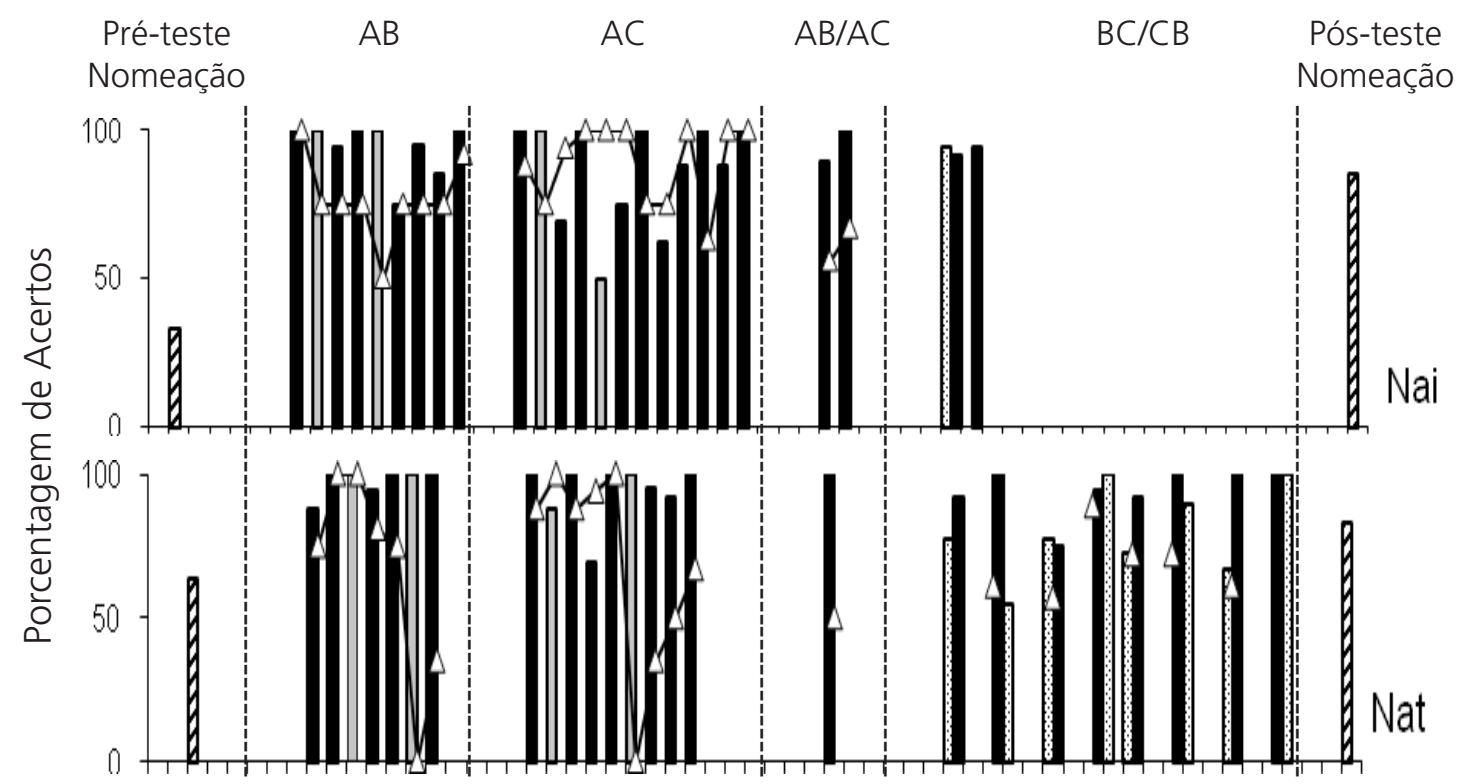

Blocos sucessivos de tentativas

Figura 1. Porcentagem de acertos dos participantes do Grupo 1 ao longo das fases de ensino e testes. As barras hachuradas representam pré e pós-testes de nomeação de figuras, as barras pretas e cinza representam tentativas de ensino das relações $A B$ e $A C$; a linha sobreposta às barras representa o desempenho no ensino de imitação de palavras; e as barras pontilhadas representam os testes de formação de classes.

que compunham o bloco de tentativas ou possibilidades de emissões daquele bloco.

As respostas de vocalização foram, posteriormente, analisadas por um segundo observador sem familiaridade com o procedimento. Foram avaliadas $33,5 \%$ das tentativas de vocalização $(99 / 295)$. A média de concordância foi de $76,7 \%$, calculada pelo número de concordâncias dividido pelo número total de tentativas de vocalização (concordância mais discordância) multiplicado por 100 (Kazdin, 1982).

As principais discordâncias referiram-se à transcrição de erros; não foram registradas discordâncias em relação aos acertos. No caso da vocalização sem correspondência com a palavra ditada no ensino, embora os observadores percebessem de forma diferente alguns dos fonemas, eles foram constantes nas transcrições realizadas para a mesma palavra vocalizada pelo participante. A título de exemplo, quando a palavra a ser vocalizada era /figo/ e a participante Nat, no pré-teste, emitiu com distorção, enquanto um observador registrou sistematicamente /bíblia/, o outro registrou /vivia/. No pós-teste, a participante Nat emitiu /figo/, o que foi registrado com 100\% de concordância entre os observadores, nas tentativas de vocalização dessa palavra.

As duas participantes do Grupo 1 apresentaram baixo desempenho no pré-teste de 
nomeação das três figuras selecionadas para o experimento. Nai apresentou 33\% de acertos e Nat, 64\%, conforme barras hachuradas na extrema esquerda da Figura 1. Foram, então, expostas ao ensino de vocalização, que encadeava as tentativas de ecoico às de discriminações auditivo-visuais. A palavra era ditada pelo alto-falante: o participante deveria repeti-la e, em seguida, selecionar a figura que se relacionava com a palavra ditada. As linhas com triângulos na Figura 1 representam o desempenho de vocalização, e as barras, o desempenho em seleção. Cada barra preta representa o desempenho em uma relação condicional auditivo-visual, e as barras cinza indicam o bloco em que foi apresentada uma nova relação auditivo-visual. $\mathrm{O}$ ensino de discriminações auditivo-visuais foi efetivo para as duas participantes (Nat e Nai), que atingiram, com poucas exposições aos blocos de tentativas, $100 \%$ de acertos. O maior número de exposições foi de 12 blocos para Nai no ensino das relações AC. O desempenho preciso foi mantido por ambas no bloco que apresentava as relações AB e AC misturadas em um mesmo bloco. Durante o ensino de vocalização que se sobrepôs ao ensino das relações auditivo-visuais, embora o desempenho se mostre oscilante, ambas aprenderam a repetir as palavras ditadas.

Nai apresentou 100\% de acertos na relação A1B1 e 100\% de acertos na vocalização da primeira palavra. Então, foi exposta a relação A2B2, em que, embora obtivesse 100\% de acertos nas tarefas de seleção, o desempenho na vocalização da palavra ditada não foi preciso $(75 \%)$. Por esse motivo foi exposta novamente a um bloco semelhante, com a mesma relação, para que pudesse ser exposta novamente a tarefas de imitação vocal. Como o desempenho de imitação da palavra A2 não se modificou e o desempenho em seleção de B2 na presença de A2 continuou preciso, a participante foi exposta à relação A3B3, sob pena de a repetição da tarefa se tornar muito aversiva. Quando exposta à relação A3B3, o desempenho em seleção foi preciso; porém, o desempenho em vocalização foi de $50 \%$ de acertos. Após mais três exposições a blocos de tentativas semelhantes da mesma relação, o desempenho em imitação vocal atingiu 75\% de acertos. Durante o ensino AB, toda vez que uma nova palavra era inserida, o desempenho em vocalização decaía. Essa característica é evidente na sobreposição do triângulo à barra cinza. Todas as vezes que havia um erro na repetição de palavras, o experimentador apresentava pistas orofaciais. Quando as três relações $A B$ foram exibidas em um mesmo bloco e em ordem aleatória, o desempenho em seleção foi de $100 \%$, e o de vocalização foi de $92 \%$, superior aos desempenhos em vocalização nas tarefas de ensino quando apresentadas isoladamente. Durante o ensino da relação AC, embora o desempenho em seleção de figuras abstratas fosse adquirido gradualmente em 12 blocos de tentativas, o desempenho em vocalização de palavras chegou à precisão; porém, a porcentagem de acertos decaiu durante o ensino $\mathrm{AB}$ e $\mathrm{AC}$ combinados, quando a mesma palavra foi relacionada a duas figuras diferentes. Nai demonstrou formação de classes logo na primeira exposição aos testes BC/ CB e um desempenho de $85 \%$ no pós-teste de nomeação.

Nat iniciou o ensino de seleção e de vocalização com erros, obtendo 88\% e 75\% de acertos, respectivamente. Contudo, quando exposta à relação A2B2, chegou à precisão em ambas as tarefas. Quando foi exposta ao 
bloco que mistura as relações A1B1 e A2B2, o desempenho foi bom em seleção (superior a 94\% de acertos), mas não em vocalização. Com a inserção da terceira relação (A3B3), embora o desempenho em seleção de figuras fosse de $100 \%$, não emitiu nenhuma vocalização corretamente, e esse desempenho interferiu nas vocalizações já emitidas corretamente no bloco que misturava as três relações condicionais, obtendo $100 \%$ de acertos em seleção, mas 33\% de acertos em vocalização. Ainda que o desempenho em imitação de palavras fosse baixo nas relações $A B$, o ensino das relações AC foi iniciado, pois, embora a tarefa de seleção fosse diferente, a tarefa de vocalização se mantinha a mesma. Esse ensino favoreceu que o seu desempenho em imitação de palavras se recuperasse gradualmente. Nat encerrou o ensino AC com 67\% de acertos na repetição de palavras e necessitou de pistas orofaciais em todos os blocos. Embora na linha de base integral (AB/AC) ela demonstrasse $100 \%$ de acertos nas tarefas de seleção, seu desempenho em vocalização foi de apenas 50\% de acertos. Quando exposta aos testes de formação de classes, a emergência ocorreu de forma atrasada, necessitando de repetidas exposições (sete) aos testes $\mathrm{BC} / \mathrm{CB}$ (barras pontilhadas) e revisão de linha de base (barras pretas). Uma particularidade da rotina experimental conduzida com Nat foi que, mesmo durante os testes de formação de classes, a repetição de palavras foi fortalecida, isto é, sempre que o estímulo auditivo era apresentado, durante as tentativas de linha de base, era solicitada sua repetição. Embora o desempenho em imitação de palavras durante os testes de formação de classes também oscilasse bastante, o melhor resultado obtido foi de $89 \%$ de acertos, na terceira exposição. Em relação à formação de classes, o desempenho atingia níveis melhores de acertos sempre que tentativas de formação de classe e de linha de base eram apresentadas em blocos separados, como na sexta e oitava exposições, chegando a 100\%. O escore nos testes de formação de classes começou a melhorar após a exposição a um bloco de tentativas visual-visual com relações de identidade (BB/CC), conforme ilustra o quarto conjunto de barras nos testes BC e CB da Figura 1. No pós-teste de nomeação, seu desempenho chegou a $83 \%$ de acertos.

As duas participantes do Grupo 2 apresentaram um desempenho razoável no pré-teste de nomeação. Cam obteve 60\% e Tal, $67 \%$ de acertos, conforme barras hachuradas da extrema esquerda da Figura 2.

No Grupo 2, o ensino de imitação de palavras foi realizado antes da exposição ao ensino das relações auditivo-visuais. A participante Cam foi exposta a dois blocos consecutivos de tentativas de imitação de palavras, e o desempenho no último bloco foi de $87 \%$ de acertos. No ensino das relações auditivo-visuais, a participante Cam aprendeu as relações AB e AC de forma rápida (com um número pequeno de exposição aos blocos de tentativas) e com poucos erros. Demonstrou emergência das relações BC e CB, obtendo 100\% de acertos já na segunda exposição. No pós-teste de nomeação, obteve $80 \%$ de acertos.

A participante Tal também foi exposta a dois blocos consecutivos de tentativas de imitação de palavras, e o desempenho no último bloco de tentativas foi de $92 \%$ de acertos. Quando foi exposta ao ensino das relações auditivo-visuais, seu desempenho foi preciso. Nos testes de formação de classes, foi consta- 
tada a emergência das relações BC e CB; porém, durante as cinco exposições às sondas, $\mathrm{O}$ resultado oscilou entre 78 e $97 \%$ de acertos. No pós-teste de nomeação, obteve $76 \%$ de acertos nas vocalizações emitidas.

\section{DisCUSSÃo}

Este trabalho demonstrou que todos os participantes aprenderam a relação entre uma mesma palavra ditada e duas figuras distintas (convencionais e abstratas). Todos os participantes demonstraram que o ensino pode gerar relações derivadas das ensinadas, demonstradas pelos testes de formação de classes nos quais as figuras relacionadas à mesma palavra falada eram também relacionadas entre si.
Os resultados deste estudo confirmam evidências anteriores de que deficientes auditivos pré-linguais que receberam o implante coclear podem aprender relações entre som e figuras, e essas relações assumem funções simbólicas (Almeida-Verdu et al., 2008), não se limitando a relações do tipo "se-então" (Sidman \& Tailby, 1982), assim como já atestado em outras populações com repertório verbal mínimo (Carr, Wilkinson, Blackman, \& McIlvane, 2000).

As duas condições de ensino de repetição de palavras adotadas, quais sejam, repetição de palavras encadeada a uma discriminação condicional (Grupo 1) e repetição de palavras antes do ensino da relação auditivo-visual (Grupo 2), se mostraram promisso-

\section{Grupo 2}

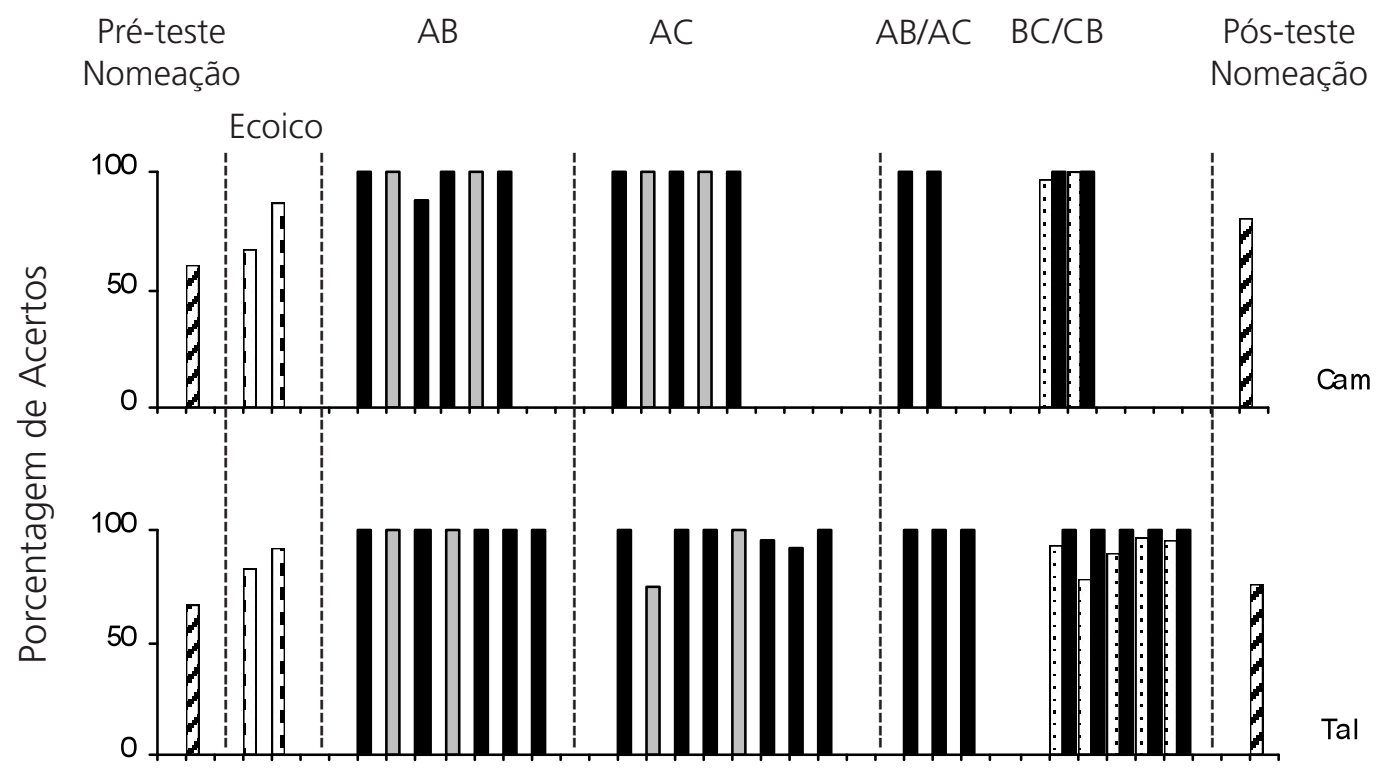

Blocos sucessivos de tentativas

Figura 2. Porcentagem de acertos dos participantes do Grupo 2 ao longo das fases de ensino e testes. As barras hachuradas representam pré e pós-testes de nomeação de figuras; as barras tracejadas representam o desempenho no ensino de imitação de palavras; as barras pretas e cinza representam tentativas de ensino das relações AB e AC; e as barras pontilhadas representam os testes de formação de classes. 
ras para a melhora da vocalização em tarefas de nomeação de figuras. Evidências de que o ensino de repetição de palavras pode ser uma condição importante para o aumento da correspondência ponto a ponto entre a nomeação de figuras e a palavra ditada correspondente podem ser observadas não só a partir da comparação entre as porcentagens de acertos obtidas pelos participantes nas tarefas de pré e pós-teste de nomeação deste estudo, mas também da comparação com dados obtidos em estudos anteriores (Almeida-Verdu et al., 2008; Battaglini, 2010). Esses estudos, embora tenham empregado delineamentos distintos no ensino das relações condicionais, têm em comum a avaliação da nomeação de figuras no pós-teste sem que se tenha empregado algum procedimento de modelagem da topografia vocal. Contudo, uma investigação mais precisa do efeito da imitação de palavras pode ser realizada a partir de um delineamento de grupo ou delineamento de linha de base múltipla com ensino gradual e sistemático para pequenos grupos de palavras.

Ainda que o desempenho final entre os participantes dos dois grupos seja muito semelhante, a diferença entre o pré e pós-teste foi maior no Grupo 1. Embora o nível operante dos participantes do Grupo 1 seja mais baixo, acentuando as diferenças entre os grupos no pós-teste, a modificação da topografia vocal ao longo do experimento foi maior nesse grupo. Uma hipótese pode ser a exposição sistemática e intensiva à palavra ditada e solicitação de sua repetição, realizada tentativa a tentativa. Nesse caso, as participantes do Grupo 1 receberam maior treino em repetição de palavras. As pistas orofaciais podem ter exercido papel importante no controle de estímulos para a vocalização, já que, após uma palavra ser ditada, a imitação desta sempre acontecia, com correspondência ponto a ponto, somente após a apresentação dos movimentos orofaciais pelo experimentador. Pesquisas com ouvintes têm demonstrado que ver uma pessoa falar (o que inclui estimulação auditiva e visual) ativa áreas corticais responsáveis pela audição e visão, obtidas em imagens de Pet-Scan (Giraud \& Truy, 2002). Nesse caso, apresentar os movimentos orofaciais sobrepostos à palavra ditada parece ser importante na aprendizagem de repetição de palavras e funcionar como estímulos compostos, de tal forma que, após a retirada de uma dimensão do estímulo (nesse caso, movimentos orofaciais), o responder passa a ser controlado pela dimensão que permaneceu (nesse caso, a palavra ditada). Contudo, a exposição do participante a blocos que apresente estimulação visual suplementar, o registro desta e o retorno a blocos em que a estimulação é puramente auditiva devem ser mais bem controlados em estudos futuros.

Após essas condições de ensino e teste, todos os participantes demonstraram melhora no desempenho de nomeação, com resultados superiores a $80 \%$, como as participantes Nas, Nat e Tal, e chegando a 100\%, como Tam e Cam. E este é o resultado que se pretende destacar. Se no estudo anterior (Almeida-Verdu et al., 2008), após o ensino de relações condicionais e testes de formação de classes, os participantes não demonstraram desempenhos em nomeação compatíveis com seus pares ouvintes, isso se deve em parte porque o desempenho de vocalizar palavras com correspondência ponto a ponto à palavra ditada não foi alvo direto de ensino. 
Neste estudo, observaram-se mudanças no desempenho de nomeação após os participantes terem sidos expostos às condições de ensino de repetição de palavras e independente do momento em que a repetição de palavras foi ensinada. Nesse caso, a vocalização foi alvo direto de ensino. A sequência em que as condições de ensino e teste foram conduzidas forneceu a segurança necessária para afirmar que a nomeação somente se estabeleceu após um ensino sistemático e programado da imitação vocal.

Este estudo converge com a literatura que descreve a independência funcional entre os comportamentos de ouvir e falar (Gaia, 2005; Guess, 1969; Skinner, 1957). Estudos como esse, sobre as condições que devem estar presentes para a expansão de repertórios de ouvir e de falar, oferecem uma oportunidade muito interessante de se compreenderem as relações de independência e interdependência entre os repertórios de falante e de ouvinte. De acordo com Skinner (1957), para um estudo preciso sobre as propriedades do ouvir e falar, é necessário tomar esses repertórios como funcionalmente independentes, isto é, o fato de um ser adquirido não requer necessariamente que o outro seja; mas deve-se assumir que ouvir e falar possam se inter-relacionar, desde que haja ensino programado com essa finalidade.

Futuras pesquisas devem controlar o critério de aprendizagem para avançar no ensino (deve ser obtida a precisão nas vocalizações) para se averiguarem os efeitos do ensino de repetição de palavras.

\section{REFERÊNCIAS}

Almeida-Verdu, A. C. M. (2002). O enfoque comportamental na pesquisa em processos perceptuais auditivos: aproximação entre a audiologia e a análise do comportamento (aplicada). Arquivos Brasileiros de Psicologia, 54(3), 240-254.

Almeida-Verdu, A. C. M., Huziwara, E. M., de Souza, D. G., de Rose, J. C., Bevilacqua, M. C., Lopes Jr, J., Alves, C. O., \& McIlvane, W. J. (2008). Relational learning in children with deafness and cochlear implants. Journal of the Experimental Analysis of Behavior, 89, 407-424.

Battaglini, M. P. (2010). Reconhecimento de palavras, nomeação de figuras e de palavras impressas em surdos implantados pré-linguais (Dissertação de mestrado). Faculdade de Ciências, Unesp, Bauru, SP, Brasil.

Bevilacqua, M. C. (1998). Implante coclear multicanal: uma alternativa na habilitação de crianças surdas (Tese de livre-docência). Faculdade de Odontologia de Bauru, Universidade de São Paulo, Bauru-SP, Brasil.

Carr, D., Wilkinson, K. M., Blackman, D., \& McIlvane, W. J. (2000). Equivalence classes in individuals with minimal verbal repertoires. Journal of the Experimental Analysis of Behavior, 74, 101-114.

Cuvo, A. J., \& Riva, M. T. (1980). Generalization and transfer between comprehension and production: A comparison of retarded and nonretarded persons. Journal of Applied Behavior Analysis, 13, 315-331.

da Silva, W. R., de Souza, D. G., de Rose, J. C., Lopes Jr., J., Bevilacqua, M. C., \& McIlvane, W. J. (2006). Relational learning in deaf children with cochlear implants. Experimental Analysis of Human Behavior Bulletin, 24, 1-8.

Dube, W.V. (1991). Computer software for stimulus control research with Macintosh computers. Experimental Analysis of Human Behavior Bulletin, 9, 28-39. 
Eikeseth, S., Nesset, R. (2003). Behavioral treatment of children with phonological disorder: The efficacy of vocal imitation and sufficient-response-exemplar training. Journal of Applied Behavior Analysis, 36, 325-337.

Gaia,T. F. (2005). Diagnóstico de habilidades lingüísticas e de funções simbólicas de estímulos auditivos em portadores de implante coclear (Dissertação de mestrado). Programa de Pós-graduação em Educação Especial, Universidade Federal de São Carlos, São Carlos, SP, Brasil.

Giraud, A. L., \& Truy, E. (2002). The contribution of the visual areas to speech comprehension: A PET study in cochlear implants patients and normal-hearing subjects. Neuropsychologia, 40(9), 1562-1569.

Guess, D. (1969). A functional analysis of receptive language and productive speech: acquisition of the plural morpheme. Journal of Applied Behavior Analysis, 2, 55-64.

Kazdin,A. E. (1982). Single case research designs: Methods for clinical and applied settings. New York: Oxford.

Löhle, E., Frischmuth, S., Becker, M. H., Flamm, K., Laszig, R., Beck, C., \& Lehnhardt, E. (1999). Speech recognition, speech production and speech intelligibility in children with hearing aids versus implanted children. International Journal of Pediatric Otorhinolaryngology, 47, 165-169.

Löhle, E., Holm, M., \& Leheneardt, E. (1999). Preconditions of language development in deaf children. International Journal of Pediatric Otorhinolaryngology, 47, 171-171.

McMorrow, M. J., Foxx, R. M., Faw, G. D, \& Bittle, R. G. (1987). Cues-pause-point language training: Teaching echolalics functional use of their verbal labeling repertoires. Journal of Applied Behavior Analysis, 20, 11-22.

Moret, A. L. M., Bevilacqua, M. C., \& Costa, O. A. (2007). Implante coclear: audição e linguagem em crianças deficientes auditivas pré-linguais. Pró-Fono Revista de Atualização Científica, 19(3), 295-304.

Osberger, M. J. (1993). Speech intelligibility of children with cochlear implants, tactile aids, or hearing aids. Journal of Speech, Language, and Hearing Research, 36, 186-203.

Sidman, M. (1985). Aprendizagem-sem-erros e sua importância para o ensino do deficiente mental. Psicologia, 11(3), 1-15.

Sidman, M., \& Tailby, W. (1982). Conditional discriminations vs. matching to sample: An expansion of the testing paradigm. Journal of the Experimental Analisys of Behavior, 37, 5-22.

Skinner, B. F. (1957). O comportamento verbal. São Paulo: Cultrix.

Stoddard, L. T., de Rose, J. C. C., \& McIlvane, W. (1986). Observações curiosas acerca do desempenho deficiente após a ocorrência de erros. Psicologia, 12(1), 1-18.

Stuchi, R. F., Nascimento, L. T. Bevilacqua, M. C., \& Brito Neto, R.V. B. (2007). Linguagem oral de crianças com cinco anos de uso do implante coclear. Pró-Fono Revista de Atualização Científica, 19(2), 167-176.

Svirsky, M. A., Robbins, A. M., Kirk, K. I., Pisoni, D. B., \& Miyamoto, R. T. (2000). Language development in profoundly deaf children with cochlear implants. Psychological Science, 11(2), 153-158.

Terrace, H. S. (1963). Discrimination learning with and without "errors". Journal of the Experimental Analysis of Behavior, 6, 1-27.

Terrace, H. S. (1966). Control del estimulo. In W. K. Honig, \& J. E. R. Stadon, (Eds.). Manual de conducta operante. México:Trillas.

Truy, E., Lina-Granade, G., Jonas, A., Martinon, G., Maison, S., Girard, J., Porot, M. \& Morgon, A. (1998). Comprehension of language in congenitally deaf children with and without cochlear 
implants. International Journal of Pediatric Otorhinolaryngology, 45, 83-89.

\section{Nota dos autores:}

A pesquisa relatada neste artigo foi apoiada pela Fapesp (Processo no 2003/09928-4) e pelo CNPq (Edital Universal - Processo no
473880/04). A segunda e a terceira autoras são bolsistas de pesquisa do CNPq. Agradecemos a Sandra de Lima Ribeiro dos Santos pela colaboração na coleta de dados.

Para mais informações sobre este artigo, entrar em contato com Ana Cláudia A. M. Verdu: anaverdu@fc.unesp.br. 